\title{
BIREGIONAL COOPERATION FOR ADVANCING GAMIFICATION IN TRANSPORT POLICIES AND INFRASTRUCTURE IN THE EUROPEAN UNION AND LATIN AMERICA AND THE CARIBBEAN1
}

\author{
Ioana Antoaneta DODI, PhD \\ National University of Political Studies and Public Administration \\ Bucharest/Romania
}

\begin{abstract}
The globalization process is constantly growing and actors in the international scene have to find ways to adapt to the changes that this makeover involves. Therefore, there has been an increased cooperation between the European Union and Latin America and the Caribbean in many policy areas, including transport, especially in terms of access, affordability and sustainability. The Vienna Declaration of the Fourth ALC-UE Summit of Heads of State and Government from 2006 mentions the encouragement towards European and Latin American and Caribbean financial institutions to support physical integration by means of interconnectivity, network infrastructures, notably in the fields of energy, transport, telecommunications and research. The Lima Declaration of the Fifth ALC-UE Summit of Heads of State and Government from 2008 moves a step forward and comprises the fact that the states from the two regions will develop bi-regional energy cooperation regarding improvement of energy services, inter alia, in the metropolitan public transport. Moreover, the Madrid Declaration of the Sixth ALC-UE Summit of Heads of State and Government from 2010 refers

1The article is part of the development of a study on the application of the game approach in logistics and transport training (Output Title O4) under the Erasmus + strategic partnership project „Building an innovative network for sharing of best educational practices, incl. game approach, in the area of international logistics and transport", Project number: KA203 /HE-25 / 13.09.2019
\end{abstract}


to energy savings in all sectors of the economies, including transports, meanwhile the Santiago Declaration of the First UE-CELAC Summit of Heads of State and Government from 2013 prioritises the improvement of policies and providing, among others, adequately resourced basic health services, water and sanitation, housing, education, public transport and energy, besides strengthening the Latin America Investment Facility, to improve integration, energy and transport infrastructures, energy efficiency, renewable energy. Therefore, this paper aims to analyse best practice cases from both regions in terms of gamification of transport policies and infrastructure, in order to highlight the the potential of the biregional consolidated cooperation for advancing gamification (in view of modern, sustainable, affordable, efficient transport policies, networks and infrastructure), the financial and political instruments that can be used in this sense and the mutual benefits that it would bring for the participant actors.

Keywords: biregional cooperation; sustainable transport; mobility efficiency; gamification.

\section{INTRODUCTION}

Globalization seems to be a fashionable word in political science in the last 30 years, but there is another G-word that is joining it in the spotlight, which is gamification. The two concepts amplify each other, especially given the wide spread of technology nowadays and the benefits that citizens have in the case of easy access to public services.

Gamification is defined by Sgueo as "the use of game-design elements (e.g., rankings, levels, and badges) into non-game contexts", implying playful dynamics such as an artificial conflict among users (competition), a set of rules to govern such conflicts and quantifiable outcomes (rewards) (Sgueo 2020,1). As such, it represents an unconventional way to approach the relationship between authorities and citizens, especially since, most of the times, the aforementioned is a rigid, hard to understand or not so interactive one. It can be extremely useful 
in transport policies, whereas "the EU defines a smart city as 'a place where traditional networks and services are made more efficient with the use of digital and telecommunication technologies, for the benefit of its inhabitants and businesses'" (Eurostat Urban Europe statistics on cities, towns and suburbs 2015, 102).

Although "well-designed public transport services are of crucial importance to ensure sustainable and environmentally friendly mobility to all citizens of nowadays cities" (Drakoulis, Belloti, Bakas, Berta, Paranthaman, Dange, Lytrivis, Pagle, De Gloria and Amditis 2018, 1), the changes in transport policies can be difficult to apply, mostly if they depend in a certain measure on the good behaviour of the beneficiaries. Therefore, gamification can be a tool for change in transport policies given the fact that its features can persuade travellers to engage from the beginning into the policy's new framework, thus internalising it on the long term.

Even if a transport policy is efficient in a certain city, it is rather difficult to apply it the same in another one, because of the diversity of factors that may become obstacles in this sense, starting from the infrastructure features to the availability of the citizens that are in fact the ones respecting in real life the respective policy in a more or less correct way. Considering all this, one may advance the question upon the feasibility of creating a uniform perspective or even more, a common policy in two different cities, states or regions, especially since "Two cities with a same population, area and number of transport stops can still have a radically different access to public transport" (Poelman and Dijkstra 2015, 2). The answer to this may lay in the use of gamification in the processes of designing and implementing the transport policies, because of its flexibility (having, for example, the same rules for the game, but adapting its content to the specific context). Hence, even in apparently incompatible conditions, gamification can bring the same results.

When taking into account biregional cooperation between two large and heterogeneous areas (even among their own composing states) as the European Union and Latin America and the Caribbean, the first things that come to mind are the common values that unite them. One of these is the environmental protection, increasingly needed to be considered in the sustainable development 
of economic activities, energy and, of course, transport. Furthermore, there are common challenges that stakeholders (national or local authorities, citizens, NGOs) in both regions face and for which they seek answer to. An eloquent example may be hard traffic conditions that overwhelmed cities find harder and harder to handle. From this point of view, it is important to research the implications that using gamification in transport policies can have on the eurolatinamerican cooperation, especially taking into account the Strategic Partnership between the European Union and Latin America and the Caribbean. Therefore, this paper analyses the potential that gamification has for the transport policy improvement, mobility effectiveness, traffic decongestion, the pre-existing factors favouring or not the biregional cooperation for all the above mentioned and best practice cases from both areas.

\section{BIREGIONAL COOPERATION}

In the times we are living, both individuals and states, all have to face challenges that threaten to enlarge the existing gap between the two: populism, fake-news, political disenchantment, democratic deficit, growing needs and limited resources. Therefore, one of the major queries regards the way to bring the two actors together and to make them accomplish their obligations in order to achieve the mutual social well-being (for example, in transport, on one hand, the state may not assure quality and on-time busses, thus affecting the passengers, and on the other, the individual may not buy the tickets, thus affecting the state). Gamification might be a good solution in this sense, given the fact that it implies that one part will have so much to gain as efforts it brings into the game.

Moreover, in the case of cooperation among heterogeneous regions such as the European and Latin American one, gamification can help achieve joint results, although different backgrounds. In the following section, there will be analysed the political and financial instruments that are available for this endeavour, but also examples of implementation of gamification in transport that have already proven successful and that can serve as models for future assistance. 


\subsection{Political Instruments: EU-LAC/CELAC Summits}

The EU-LAC/CELAC Summits of Heads of State and Government represent the main political framework of the relations between the actors of the two regions and an adequate environment for negotiations and joint actions in the area of transport, given that this is one of the main areas that have to run smoothly in the perspective of increasing mobility and decreasing average time available for task solving. Mobility Management represents "policies and strategies to reduce travel demand and number of vehicle trips and encourage modal shift toward more sustainable transport" (Nakashimaa, Satoa and Maruyama 2017, 2344), areas of interest for stakeholders in both regions.

\subsubsection{The Rio Summit}

The First ALC-UE Summit of Heads of State and Government marks a new phase for the relations of Latin America and the Caribbean on one side and the European Union on the other, given the fact that it entailed the creation of the Strategic Partnership between the two regions. Among other substantial policy areas, transport was one of the components of the resulting declaration of this Rio Summit of 1999, through the agreement that the signing states would "encourage technology transfer in order to improve the processes and standards of economic links between the European Union and Latin America and the Caribbean in the fields of the production of goods, foreign trade, port infrastructure, and telecommunications and transport" (Rio Summit Declaration 1999, 7) and would "favour innovation and technology transfer in order to obtain greater economic and technical linkage between the two regions in the fields of production of goods and services, foreign trade, infrastructure, and telecommunications and transport" (Rio Summit Declaration 1999, 10), anticipating thus the powerful effect that guaranteeing technological infrastructure at similar levels would have for setting common actions in transport for instance, fact that of course, would also generate progress both at an individual level (for personal or professional aspects) and at national or 
biregional level (for instance for "liberalisation of trade and the intensification of economic co-operation") (Rio Summit Declaration 1999, 7).

\subsubsection{The Viena Summit}

After the 2002 and 2004 Summits in Madrid and Guadalajara, where other policies have been at a centre stage of the discussions, it was in 2006 at the Viena EU-LAC Summit of Heads of State and Government that cooperation in the area of transport reappeared as topic, encouraging "European and Latin American and Caribbean financial institutions to support physical integration by means of interconnectivity, network infrastructures, notably in the fields of energy, transport, telecommunications and research" (Viena Summit Declaration 2006, 11). Once a certain topic is established as a priority for joint action, there is a strong demand for the financial resources that should sustain the development of the stipulated measures, so the endorsement that the authorities from both regions have made is an evidence of their intentions to tie the connections in the areas of energy, transport, telecommunications and research, which are all interrelated in the case of gamification of transport policies.

\section{1..The Lima Summit}

In 2008, the Fifth Latin America and Caribbean-European Union Summit in Lima highlights the call for "diversification of energy sources; better access to the production and use of clean and low carbon intensive energies; improvement of energy efficiency processes; development of new technologies; production and use of environmentally sustainable energy sources; and improvement of energy services, inter alia, in the metropolitan public transport" (Lima Summit Declaration 2008, 12). City transportation becomes thus a concern that grows directly proportionally with the population within it (that tends to expand), even more in the biregional perspective of mobility (especially the one on short term, like in the case of business or vacation journeys to cities where it is important to not waste time in traffic for example) or sustainability (because 
pollution and climate change tackling is a global problem that has no frontiers and that must be confronted in a joint method).

Unfortunately, the 2008-2010 financial and economic crises determined waves of austerity measures and budgetary cuts, especially in the European Union (which also had to face the Euro Crisis) that, although counterproductive, hit primarily sections regarding stimulating green energy, combating traffic and pollution etc.

\subsubsection{The Madrid Summit}

The Madrid 2010 Summit Declaration of Heads of State and Government marks that they "regard as essential contributions to the eradication of poverty and to the achievement of the Millennium Development Goals, the diversification and complementarity of the energy matrix, including through the promotion of renewable energy, as well as greater energy efficiency and energy savings in all sectors of the economies, including transports, changes in the current patterns of consumption and production, improved regional energy interconnectivity and peoples' access to energy services" (Madrid Summit Declaration 2010, 4). This point draws special attention regarding the use of gamification in public policies, especially if we correlate that with the name given to the Declaration, which is Towards a new stage in the bi-regional partnership: innovation and technology for sustainable development and social inclusion, emphasizing in a particular manner the importance of the biregional cooperation in the areas of technology and innovation.

\subsubsection{The Santiago and Brussels Summits}

During the Santiago Biregional Summit in 2013 it was agreed that "in order to ensure peoples' quality of life and the environment in which they live, we reiterate our commitment to work steadily towards eradicating poverty, fostering equality, including gender equality, and social inclusion, and to protect the most vulnerable groups - including indigenous peoples and their communities - by improving policies and providing, among others, adequately resourced basic health services, water and sanitation, housing, education, public 
transport and energy" (Santiago Summit Declaration 2013, 5), thus underlining the value of public transport among indispensable public services that citizens must benefit from.

The presidents and prime ministers "reiterate the right of citizens to participate in the formulation, implementation and monitoring of public policies" (Santiago Summit Declaration 2013, 5), so it can be noticed an advance also towards the involvement of individuals in managing the political issues. In this sense, gamification seems the perfect match for this kind of purpose.

Moreover, encouragements were made for creating the Caribbean Investment Facility and "strengthening the Latin America Investment Facility, to improve integration, energy and transport infrastructures, energy efficiency, renewable energy, sustainable communications networks, and to promote sustainable development through stronger social services and increased support to SMEs" (Santiago Summit Declaration 2013, 14), thus manifesting the preoccupation for an instrument that would deliver the resources required for the costs that are implied in the process. The importance for this is emphasized also by the recognition in the Brussels Declaration from 2015 of the "contribution that the EU's Latin America Investment Facility and the Caribbean Investment Facility can play in mobilising financial resources for development and in leveraging funds for jointly identified priority sectors and projects, such as climate change adaptation and mitigation, transport infrastructure, energy, connectivity and promotion of the private sector, including micro, small and medium-sized enterprises" (Brussels Summit Declaration 2015, 12).

Because it is the first biregional summit celebrated after the creation of the Community of Latin American and Caribbean States, it brought an even more political weight, given the fact that this way we were not only taking into account national actors, but also supranational ones, offering a counterpart for the European Union in the CELAC. 


\subsection{Financial Instruments: European Funding Programmes}

The European Union's core is based on its values, both internally and externally, so cohesion and solidarity principles guide many of its decisions and policies, all the more when there is also a possibility of collaboration that might bring mutual benefits and joint progress, as in the case of the Strategic Partnership between the EU and Latin America and the Caribbean. Therefore, besides the funds in the Development Policy, there are other options that partners from both regions can apply for, as it can be noticed further.

\subsubsection{FP7 and $H 2020$}

The Viajeo Plus project (at its full name: International Coordination for Implementation of Innovative and Efficient Urban Mobility Solutions) reflects very well the power of the coordination between different regions of the world, making steps together in order to better tackle the obstacles that appear in their cities in terms of mobility or pollution. With a total budget of 2,197,000 euros, it needed a strong support that was given through the $7^{\text {th }}$ Framework Programme (FP7) European programme, at a contribution of 1,971,921 euros (Viajeo Plus Project), almost the entire amount, which would be too large to be borne by the implementing organizations alone, thus stressing once more the necessity for robust financial instruments. Like any other reforming task, financial resources are vital for the achievement of the desired results in the attempts of gamification of transport policies, especially when referred to an international cooperation venture.

The activities focused on the active uptake and transfer of knowledge and solutions between European cities and cities across the world, in particular from Latin American Countries, China and Singapore (Viajeo Plus Project Background), more exactly on effective mobility management, deployment of Clean Vehicle solutions, innovative public transport solutions, enabling infrastructure, sustainable urban logistics solutions, engaging cities (Viajeo Plus Project Work Packages), priorities that emphasizes the growing demand for action in these field, especially in a concerted manner, not by taking them into 
consideration separately, but on the contrary, in the perspective that they influence one another, as indeed it can be observed in the situation of gamification of transport policies, where by engaging citizens in ad for their cities, they can generate innovative solutions for building a sustainable urban space.

Observing the list of participants (European Commission CORDIS Viajeo Plus Project), the implication of 7 European countries (Belgium, France, United Kingdom ${ }^{1}$, Italy, Sweden, Netherlands, Germany) out of 10 states is meaningful for the interest that exists in the cooperation with the other international partners in other parts of the world (Brasil, Turkey, China).

Given that "ICT-based strategies provide a unique opportunity to enhance the links between different systems/sub-systems to facilitate the much needed transparency and coordination of actions between all actors in the urban mobility landscape" (Recommendations on Policy for future cooperation with Latin America, China and Singapore, 12), this recommendation targeted at Latin America is one of the most representative results of this European funded initiative in the context of this paper because it opens the way for insertions of gamification in transport policies.

Another element that is comprised in the gamification logic is the fact that among the key information in the Best Solutions Data Gathering Template, one refered to "What degree of co-operation was required between different stakeholders?" (di Pasquale, dos Santos, Galindo Leal and Tozzi 2016, 3286), a starting point for underlining the effect of the stakeholders' contribution in the game that is designed.

SmartSantander is another project that has benefited by the support of the European Commission through FP7 in order to develop applications and services for smart cities, experimenting with a pilot project in Spain, aiming at increasing the comfort of inhabitants and the quality of life in the city through raising the accessibility to "find a parking space or manage the city's traffic (leading to benefits in terms of time and fuel savings, as well as reductions in air

${ }^{1}$ Currently, the United Kingdom is no longer part of the European Union. 
emissions); economise water or electricity (for example, through irrigation systems for green areas, the optimisation of street lighting requirements); assist local inhabitants to make a journey (real-time information on buses, bicycles for rent, or taxis available for hire); make refuse collections more efficient (routing vehicles only to those bins that require emptying)" (European Commission, Urban Europe 2018, 8).

Urban Gamification for City Reappropriations is a recent project carried out from September 2018 to September 2020 with the support of the Horizon 2020 European Programme (European Commission CORDIS Urban Gamification), aimed at "at studying urban play in the wider frame of gamification, in order to deepen our understanding on how we can use play to affect the urban spaces and on what effects this might have on the citizens and their practices" (ReClaim Project), revealing thus a current concern for figuring out the different ways that games can be adapted and implemented in order to solve urban unpleasant issues.

Mobility Urban Values is a classic example of how citizens can alter their preferences in accordance to a set of rewards that are comprised in a game that regards urban transport. Financed through the Horizon 2020 Programme, it is implemented in Amsterdam, Barcelona, Fundão, Ghent, Helsinki and Palermo (being about to be extended to another 10 cities), from 2017 to 2020 and offers "get points every time you move in a sustainable way: walking, cycling, using public transports and carpooling", even leading to a confrontation in MUV Sustainable City Tournament (Innovation and Networks Executive Agency 2019, 15).

\subsubsection{The Latin America Investment Facility and the Caribbean Investment Facility}

The Latin America Investment Facility (LAIF) "allows the European Union to engage in projects that would have been outside the scope of conventional development cooperation instruments, in a region where an increasing number of countries are looking for different approaches, innovative instruments and new forms of tailored support for investment" (Latin America Investment Facility), with a total of 31 bilateral and 15 multilateral projects developed (Latin 
America Investment Facility Facts and figures). Moreover, the LAIF also has a research component that allows dissemination of key aspects that initiators of gamification in transport policies must be aware of, like for example the fact that "using private resources or transferring more responsibilities and risks to the contractor does not imply a loss of control over the information and conditions of the system implementation" (Banco de Desarrollo de América Latina, Agence Francaise de Developpment, Unión Europea 2018, 54). Projects such as Urban Public Transportation Improvement Program or Sustainable Transport Networks are the ones that have the smallest budget ( 3 million euros each) from all the approved project by the facility that amount to 4,8 or even 10 million euros (European Commission LAIF Blending operations).

The Caribbean Investment Facility (CIF) aimes "to contribute to economic development and growth, integration at regional level and poverty reduction through the mobilization of resources for strategic economic infrastructure projects and for support to the private sector" (European Commission CIF). It can prove useful for the assistance in view of introducing gamification in transport policies, given that from the very objectives, one mai find some that bring into attention on one hand the need for improving transport and on the other, the benefits of widening access to ICT tools, like the ones meant to "create better transport and energy infrastructures which promote interconnectivity, safety, security and efficiency, improve access to Information and Communication Technology (ICT) infrastructures and improve coverage at lower cost" (European Commission LAIF).

\section{BEST PRACTICES CASES FROM THE TWO REGIONS}

The 2019 statistics of the Economic Commission for Latin America and the Caribbean showed that in the region, the average percentage of urban population is of $81,2 \%$, with $81,5 \%$ in Latin America and a slightly smaller $72,2 \%$ in the Caribbean. If we correlate that with the total population of over 648 million persons in Latin America and more than 43 million in the Caribbean (Economic Commission for Latin America and the Caribbean 2020, 14), it results 
that about 528 million individuals have to move around the Latin-American cities and that the Caribbean cities must offer mobility for 31 million travellers. The European Union has a total population of 447.7 million inhabitants (European Commission Population statistics), out of which $39.3 \%$ lives in the cities, while $31.6 \%$ in towns and suburbs (European Commission Urban and rural living in the EU), summing up a $70,9 \%$ in the urban area, thus a high rate, similar to (although roughly smaller than) the ones in Latin America and the Caribbean.

Consequently, this can only induce a race for applications and services that help engage the citizens in the daily fight with traffic, pollution, complicated infrastructure and vehicle park. This is exactly one of the resons why "most contemporary imaginings of 'Smart Mobility' describe a transition of equivalent reach and significance to that of 'automobility', focusing on a range of positive changes to how we travel around" (Dochertya, Marsdenb and Anable 2017, 114). Meanwhile, "cooperation has been moved from the traditional one way (i.e. Europe to help development in Latin American/China) to the two-way cooperation in order to gather the best human resources to develop and implement more sustainable transport solutions" (Recommendations on Policy for future cooperation with Latin America, China and Singapore, 7), therefore in the following sections, some of the best practice examples can shed light over the possibilities that exist and can be taken as a model for a bidirectional transfer in view of a joint approach of the two regions, in the framework of the EuroLatin American Strategic Partnership.

\subsection{Initiatives in Latin America and the Caribbean}

Mexico City is one of the most crowded cities in the world with a population of over 21 millon inhabitants and a prognosis of more than 24 million until 2030 (United Nations 2018,4 ) that causes a congestion ranked $13^{\text {th }}$ in the World and $1^{\text {st }}$ in North America (Tomtom Traffic Index). Hence, it is very well suited for the presentation of a successful implementation of gamification in transport policies. 


\subsubsection{Mapaton}

The upcoming details of the Mapaton initiative (Laboratorio para la ciudad Mapaton) can offer a good picture of what can be done for transport in a more than busy city with the help of the very ones that are the beneficiaries of the respective policy. It aimed at enhancing the passengers' mobility in the public transport that registers 14 million daily persons using the 30 thousand minibuses, buses and vans in Mexico City. The need that generated this example of gamification of transport policy was the lack of consistent and updated information on the origin-destination bases and on the routes that could be chosen and improved in the city traffic. The proposal was to create a game in which the citizens would create maps of their journey in real time in order to create a public data base that could be used to improve the other users' ride, resulting afterwards to a reward in money and prizes for the participants, depending on their involvement. This was a very appropriate measure to take, especially since the Law to Make Mexico City an Open City, adopted and published in the Official Journal of the Federal District in October 2015, recognizes "the right of individuals to collaborate in shaping, developing and evaluating their programs, policies and actions" (Institute of Parliamentary Investigations).

\subsubsection{Data donators}

Another successful crowdsourcing experiment is Donadores de datos, whose details (Laboratorio para la ciudad Donadores de datos) bring into the spotlight a way of understanding open data as a community resource, making a case for citizens' donation of data for a common good (whether we are talking for example about localization data for transport policies or even consumption trends and eating habits for health policies). 


\subsection{Initiatives in The European Union}

\subsubsection{Ciclogreen}

The Ciclogreen project, implemented in Spain and Belgium, provides an online incentive system (web + apps) to promote cycling, walking, car-sharing and using public transport to go to work, transforming their sustainable kilometres into points that they can redeem into incentives as for example discounts in bike accessories, a free dinner or spa treatment (European Commission Investment Project Ciclogreen), showing how gamification can be inserted into daily lives of individuals with the purpose of producing changes in their behaviour in order to obtain an aggregated shift at urban level.

\subsubsection{GoEco!}

When designing a public policy, the research behind it is vital for assuring an adequate, accessible and efficient in terms of time, costs and human resource answer to the identified need. Therefore, the GoEco! Initiative came as an example for how this process can be developed with a high and pertinent coverage, more exactly involving the citizens. The upcoming details on this activity (GoEco! research project) argue the utility of gamification in transport policy. The main idea was that citizens would install GoEco! and GoEco!Tracker smartphone applications, which tracked their trips and used game elements to challenge them to modify their mobility behavior.

Once again is highlighted that gamification is more than welcomed in cooperation of different backgrounds, such as the cooperation between the European Union and Latin America and the Caribbean (an apparently difficult exercise, but easier once all the developments presented before have taken place) given that the application is available for "in two contexts largely differing in the urban settlement type and in the available mobility options: the City of Zurich (German-speaking part of Switzerland), a dense urban area, characterized by high levels of accessibility to public transport and infrastructures for slow mobility, and the Canton Ticino (Italian-speaking part of Switzerland), a region characterized by urban sprawl, where effective 
alternatives to individual cars are often missing" (Cellina, Bucher, Mangili and Ramalho Veiga Simão 2019, 5).

\section{CONCLUSIONS}

Although "games were part of the public sphere in Greek and Roman societies, and have existed in some form or other throughout the history of public power, for the first time in history, however, public regulators are looking at how to harness the motivational potential of game-design to counter disenchantment with politics and foster civic engagement" (Sgueo 2020, 2), giving the possibility to use an ordinary instrument as a way of solving a complicated aspect such as authority-citizens mutual interaction.

Transport policy is one of the most appropriate public areas suitable for gamification, given the fact that the players are already using the elements that once adapted and transposed into game features, will guarantee a full participation.

With regard to the biregional cooperation, gamification in transport policies also has a high chance of achieving impressive results given the fact that it:

a) is extremely flexible to the different backgrounds (at regional, national or local level) that it may be wanted for due to the possibility of keeping key features of the game and adapting the others

b) implies a non-rigid persuasion of the players due to the ludic approach (people will pass from free-riding to wanting to be part of the game for the fun or the reward)

c) determines a devoted compliance of the beneficiaries (once they see the functioning and the gains, individuals will not leave the game). 


\section{REFERENCES:}

- Banco de Desarrollo de América Latina, Agence Francaise de Developpment, Unión Europea. 2018. Esquemas de implantación de tecnologías inteligentes de transporte en América Latina: estudios de casos y recomendaciones. Corporación Andina de Fomento.

- Brussels EU-CELAC Summit of Heads of State and Government 2015.

- Cellina, Francesca, Dominik Bucher, Francesca Mangili and Jose Pedro Ramalho Veiga Simão. 2019. “A Large Scale, App-Based Behaviour Change Experiment Persuading Sustainable Mobility Patterns: Methods, Results and Lessons Learnt". Sustainability. 11(9):2674.

- Di Pasquale, Guido, Alessandro Santiago dos Santos, Adriano Galindo Leal and Michele Tozzi. 2016. "Innovative public transport in Europe, Asia and Latin America: a survey of recent implementations". Transportation Research Procedia. 143284 - 3293.

- Dochertya, Iain, Greg Marsdenb and Jillian Anable. 2017. "The governance of smart mobility". Transportation Research. Part A 115 (2018) 114-125.

- Donadores de datos, Laboratorio para la ciudad. https://labcd.mx/experimentos/donadores-de-datos-cdmx/.

- Drakoulis, Richardos et al. 2018. A Gamified Flexible Transportation Service for On-Demand Public Transport, IEEE Transactions on Intelligent Transportation Systems. vol. 19, no. 3 (March 2018). pp. 921-933. doi: 10.1109/TITS.2018.2791643.

- European Commission. CORDIS. Projects and Results. International Coordination for Implementation of Innovative and Efficient Urban Mobility Solutions - Viajeo Plus Project. https://cordis.europa.eu/project/id/605580.

- European Commission. CORDIS. Projects and Results. Urban Gamification for City Reappropriations, https://cordis.europa.eu/project/id/793835.

- European Commission Eurostat. 2018. Urban Europe - statistics on cities, towns and suburbs - smart cities. https://ec.europa.eu/eurostat/statistics- 
explained/index.php?title=Urban_Europe_\%E2\%80\%94_statistics_on_cities ,_towns_and_suburbs\&oldid=412180.

- European Commission Eurostat. 2015. Urban Europe statistics on cities, towns and suburbs. Publications office of the European Union.

- European Commission, Eurostat, "Urban and rural living in the EU. https:/ / ec.europa.eu/eurostat/web/products-eurostat-news/-/EDN20200207-1.

- European Commission. Eurostat. Population statistics. https:/ / ec.europa.eu/eurostat/statisticsexplained/index.php/Population_and_population_change_statistics.

- European Commission. Latin American Investment Facility. Blending operations. https://ec.europa.eu/europeaid/policies/innovative-financialinstruments-blending/blending-operations_en.

- European Commission. Caribbean Investment Facility, https:/ / ec.europa.eu/europeaid/regions/latin-america/caribbeaninvestment-facility_en.

- European Commission. Investment Project Ciclogreen. https:/ / ec.europa.eu/eipp/desktop/en/projects/project-9625.html.

- Economic Commission for Latin America and the Caribbean (ECLAC). 2020. Statistical Yearbook for Latin America and the Caribbean 2019 (LC/PUB.2020/2-P). Santiago de Chile.

- Gianluca, Sgueo. 2020. "Gamification". In The Palgrave Encyclopedia of Interest Groups, Lobbying and Public Affairs, edited by Phil Harris, Alberto Bitonti, Craig Fleisher, Anne Skorkjær Binderkrantz. Cham: Palgrave Macmillan.

- GoEco!. http://goeco-project.ch/index.php/en/research-project/.

- Innovation and Networks Executive Agency. 2019. Making European cities greener Towards clean and smart mobility. Brussels.

- Institute of Parliamentary Investigations. Legislative Assembly of the Federal District, VII Legislature. Law to Make Mexico City an Open City. http:/ / www.aldf.gob.mx/archivo-1b52054447d78a831c329f25931f03a5.pdf. 
- International Coordination for Implementation of Innovative and Efficient Urban Mobility Solutions - Viajeo Plus Project. Recommendations on Policy for future cooperation with Latin America, China and Singapore.

- Latin America Investment Facility. https://www.eulaif.eu/en/aboutlaif\#whatislaif.

- Latin America Investment Facility. Facts and figures. https://www.eulaif.eu/en/facts-figures.

- Lima EU-LAC Summit of Heads of State and Government 2008.

- Madrid EU-LAC Summit of Heads of State and Government 2010.

- Mapaton. Laboratorio para la ciudad. https://labcd.mx/experimentos/mapaton/.

- Nakashimaa, Ryota, Takahiro Satoa and Maruyama Takuya. 2017. "Gamification Approach to Smartphone-app-based Mobility Management". Transportation Research Procedia. 25 2344-2355.

- Poelman, Hugo and Lewis Dijkstra. 2015. Regional Working Paper: Measuring access to public transport in European cities. European Commission Directorate-General for Regional and Urban Policy.

- ReClaim Project. https://www.tut.fi/Gamification/projects/reclaim/about-reclaim/.

- Rio EU-LAC Summit of Heads of State and Government 1999.

- Santiago EU-CELAC Summit of Heads of State and Government 2013.

- Tomtom. Traffic Index. https://www.tomtom.com/en_gb/trafficindex/ranking/?country=CA,MX,US.

- United Nations. Department of Economic and Social Affairs. Population Division. 2018. The World's Cities in 2018-Data Booklet (ST/ESA/ SER.A/417).

- Viajeo Plus Project. http://viajeoplus.eu/viajeo-plus-in-brief/.

- Viajeo Plus Project Background. http://viajeoplus.eu/background/.

- Viajeo Plus Project Work packages. http://viajeoplus.eu/work-packages/.

- Viena EU-LAC Summit of Heads of State and Government 2006. 